\title{
Adherence of Group B Streptococci to Human Rectal and Vaginal Epithelial Cell Lines in relation to Capsular Polysaccharides as well as Alpha-like Protein Genes - Pilot Study
}

\author{
MALGORZATA BODASZEWSKA-LUBAS ${ }^{1 *}$, MONIKA BRZYCHCZY-WLOCH ${ }^{1}$, PAWEL ADAMSKI ${ }^{2}$, \\ TOMASZ GOSIEWSKI ${ }^{1}$, MAGDALENA STRUS ${ }^{1}$ and PIOTR B. HECZKO ${ }^{1}$
}

\author{
${ }^{1}$ Department of Bacteriology, Microbial Ecology and Parasitology, Chair of Microbiology \\ Jagiellonian University Medical College, Cracow, Poland \\ ${ }^{2}$ Institute of Nature Conservation, Polish Academy of Sciences, Cracow, Poland
}

Received 16 December 2011, revised 30 October 2012, accepted 30 October 2012

\begin{abstract}
Streptococcus agalactiae (Group B Streptococci, GBS) constitutes a risk factor for infections of the newborns born by colonized mothers. The adherence of GBS to epithelial cells has been proved to be an important factor in the colonization of mucus membranes of both human rectum and vagina. The objective of the study was to assess the adhesion of the selected GBS strains to the human colon adenocarcinoma cell line (HT-29) and human epidermoid vulvo-vaginal cells (A-431) in relation to the capsular polysaccharides and alpha-like protein genes. GBS strains from the human sources belonging to Ia, Ib, II, III and V serotypes possessing different surface alpha-like protein genes such as the alp 2, alp 3, bca, epsilon and rib in the conventional adherence assay were examined. The adherence of GBS strains to the HT-29 cell line was considerably higher than to the A-431 cell line. For GBS serotype Ia and III, a significant difference between the adhesion to the HT-29 and A-431 cell lines was presented. The adhesion of GBS strains to the HT-29 cell line depended on alpha-like protein genes. The most adhesive ones were the GBS strains containing the rib and alp 2 genes. The adherence of GBS strains to the A- 431 cell line depended on both their serotype and alpha-like protein genes. Serotype III adhered to the A-431 cells most tightly, particularly the strains containing the $r i b$ and alp 2 genes. GBS strains containing the rib gene adhered to the HT-29 and A-431 cell lines more firmly than GBS strains containing other alpha-like protein genes.
\end{abstract}

Ke y w o r d s: adherence, alpha-like protein genes, capsular polysaccharides (CPS), cell lines, group B Streptococci (GBS)

Streptococcus agalactiae (Group B Streptococci, GBS) is a bacterium colonizing mainly the epithelial cells of the lower gastrointestinal tract and the vagina. The epidemiological data confirms the relation between the rectal and vaginal colonization of S. agalactiae in pregnant women and infections of the infants triggered by this bacterium. During the delivery there is a danger of infant colonization with GBS coming from the mother's microflora of the vagina or cervical canal through vertical transmission. Group B streptococci colonizes the infant's oral cavity and afterwards the respiratory tract and gastrointestinal tract. The risk of GBS transmission equals $70 \%$. S. agalactiae may trigger the infant's infections which can be divided, depending on time of occurrence after the delivery, into: early onset diseases (EOD) revealing mainly in the form of pneumonia and late onset diseases (LOD) most frequently manifesting in the form of meningitis and sepsis. (Schrag et al., 2000; Zależnik et al., 2000; Verani et al., 2010).
Pathogenesis of the infections triggered by GBS is a process consisting of several phases. The first one is undoubtedly bacterial adherence to the cells of the host conditioning colonization and invasion of the bacteria and influencing the course of the infection (Sohn et al., 2006). The adherence of GBS to epithelial cells of, among others: the vagina, rectum and lung progresses as a result of the interaction between the bacterial adhesins and extracellular matrix proteins (Kim et al., 2010).

The alpha-like proteins (the Alp family) constitute the best known and described GBS surface proteins. In this class of proteins we can differentiate the following: the Alp 2, Alp 3, Alp 4, Alpha C, Epsilon and Rib which are encoded by allelic genes, respectively: alp 2 , alp 3, alp 4, bca, epsilon and rib and possess the tandem repeated region in their structure reflected in the structure of a protein molecule as well as conservative $\mathrm{N}$-terminus and C-terminus. (Creti et al., 2004; Gherardi et al., 2007; Persson et al., 2008; Lachenauer et al., 2000).

* Corresponding author: M. Bodaszewska-Lubas, Department of Bacteriology, Microbial Ecology and Parasitology, Chair of Microbiology, Jagiellonian University Medical College; 31-121 Cracow, Poland, 18 Czysta Street; phone: +48 126336033 ; fax: +48 12 423 39 24; e-mail: mbodaszewska@gmail.com 
On the surface of GBS cells there are also other factors which do not function as adhesins but can influence the course of bacterial adherence to the epithelium. There exist contrary theories concerning the effect of capsular polysaccharides (CPS) on the GBS adherence to the host cells. There is a probability that CPS can insignificantly increase the bacterial adhesion capacity (Lione et al., 2005). Presumably, this can be related to the spacious effect of CPS on the process of interaction between the adhesion and the receptor on the surface of epithelial cells or repulsion of negativelycharged molecules of the sialic acid from the surface of the epithelial cells. Capsular polysaccharides condition the affinity of GBS strains to specific serotypes on the basis of differences in their structure. We can differentiate ten serotypes of S. agalactiae: Ia, Ib, II, III, IV, V, V, VII, VIII and serotype IX described in the recent years (Harrison et al., 1998; Hickman et al., 1999; Slotved et al., 2007).

The objective of this work was to evaluate and compare the adherence capacities of selected S. agalactiae strains to the human colon adenocarcinoma cell line (HT-29) and the human epidermoid vulvo-vaginal cells (A-431) as well as to prove the relation between the GBS adherence to the examined tissue lines and affiliation of the strains to serotypes (Ia, Ib, II, III, V) and the genes encoding the alpha-like proteins (alp 2, alp 3 , bca, epsilon, rib).

S. agalactiae strains came from the own collection of the Department of Bacteriology, Microbial Ecology and Parasitology, Chair of Microbiology, Jagiellonian University, Medical College. They were collected within the framework of the projects financed by the Ministry of Science and Higher Education no. 3 PO5E 08425 as well as statutory research no. K/ZDS/000648, which were conducted upon consent of the Bioethics Committee of the Jagiellonian University Medical College no. KBE/267/B/2002 and no. KBET/143/B/2007. The examined GBS strains $(n=26)$ were isolated both from unpregnant women and pregnant women as well as newborns. The reference strains such as: S. agalactiae DSMZ 2134 (Deutsche Sammlung von Microorganismen und Zellkulturen, DSMZ), S. agalactiae ATCC 12403 (American Type Culture Collection, ATCC) and S. agalactiae ATCC BAA-611 (ATCC) constituted the control group.

GBS strains represented the most common serotypes (Ia, Ib, II, III and V) marked with the use of a multiplex-PCR reaction in accordance with the procedure of Poyart et al. (2007). They also possessed genes of various surface proteins from the alpha-like family (alp 2, alp 3, bca, epsilon, rib) marked with the application of the multiplex-PCR method pursuant to the procedure described by Creti et al. (2004) and Gherardi et al. (2007). The diversity and number of alpha-like protein genes among five serotypes GBS strains (no. 26) and GBS standard strains (no. 3) are shown in Table I.

The HT-29 cell culture was conducted in DMEM medium (Ludwik Hirszfeld Institute of Immunology and Experimental Therapy, Polish Academy of Science, IITD PAN) whereas the A-431 cell culture was carried out in RPMI 1640 medium (IITD PAN) with the addition of $10 \%$ inactivated $\left(30\right.$ minutes, $\left.56^{\circ} \mathrm{C}\right)$ fetal bovine serum (SIGMA) as well as Penicillin-Streptomycin antibiotic mixture (SIGMA) at the temperature of $37^{\circ} \mathrm{C}$ in the atmosphere of increased humidity and $5 \%$ carbon dioxide concentration (HERACELL CO2 Incubator, Thermo Scientific). In order to conduct an experiment the HT-29 cell suspension of the density of $4 \times 10^{4} \mathrm{cell} / \mathrm{ml}$ and the A- 431 cell suspension of the density of $5 \times 10^{5}$ cell $/ \mathrm{ml}$ were cultured in 24 -well plates (Techno Plastic Products AG) on the bottom of which

Table I

Diversity and number of alpha-like protein genes among five serotypes GBS strains (no. 26) and GBS standard strains (no. 3).

\begin{tabular}{|c|c|c|c|c|}
\hline No. & GBS strains & $\begin{array}{l}\text { Sero- } \\
\text { type }\end{array}$ & $\begin{array}{c}\text { Alpha-like } \\
\text { protein gene }\end{array}$ & Investigated group \\
\hline 1 & K-A5 & $\mathrm{Ib}$ & $b c a$ & \multirow[t]{12}{*}{ unpregant women } \\
\hline 2 & K-A2 & III & $r i b$ & \\
\hline 3 & K-A6 & Ia & epsilon & \\
\hline 4 & K-A15 & II & $b c a$ & \\
\hline 5 & K-A18 & Ia & epsilon & \\
\hline 6 & K-A17 & $\mathrm{V}$ & alp2 & \\
\hline 7 & K-A14 & $\mathrm{V}$ & alp3 & \\
\hline 8 & K-B10 & $\mathrm{Ib}$ & epsilon & \\
\hline 9 & K-B18 & $\mathrm{Ia}$ & epsilon & \\
\hline 10 & K-B14 & III & $r i b$ & \\
\hline 11 & K-B15 & $\mathrm{Ia}$ & $b c a$ & \\
\hline 12 & K-B11 & II & $r i b$ & \\
\hline 13 & KC-A5 & Ia & epsilon & \multirow[t]{6}{*}{ pregnant women } \\
\hline 14 & KC-A11 & III & alp2 & \\
\hline 15 & KC-A13 & Ia & epsilon & \\
\hline 16 & KC-B6 & Ia & epsilon & \\
\hline 17 & KC-B11 & III & $r i b$ & \\
\hline 18 & KC-B13 & III & alp2 & \\
\hline 19 & N-A2 & II & $r i b$ & \multirow[t]{8}{*}{ newborns } \\
\hline 20 & N-A3 & II & $r i b$ & \\
\hline 21 & N-A9 & III & $b c a$ & \\
\hline 22 & N-A13 & $\mathrm{Ib}$ & $b c a$ & \\
\hline 23 & N-A10 & III & $r i b$ & \\
\hline 24 & N-B3 & $\mathrm{Ia}$ & epsilon & \\
\hline 25 & N-B4 & III & $r i b$ & \\
\hline 26 & N-B13 & III & alp2 & \\
\hline 27 & DSMZ 2134 & II & $r i b$ & \multirow[t]{3}{*}{ standard GBS strains } \\
\hline 28 & ATCC 12403 & III & alp2 & \\
\hline 29 & BAA-611 & $\mathrm{V}$ & $r i b$ & \\
\hline
\end{tabular}


microscopic cover glasses of the diameter of $12 \mathrm{~mm}$ (GREENPOL) had been placed earlier. To obtain a monolayer culture of the HT-29 cell line it was carried out on the plates for the period of 20 days and the culture medium was changed every day. The A-431 cell culture on the plates was continued for the period of 48 hours (Strus et al., 2001).

In order to assess vitality and density of the examined tissue lines, the cells were trypsinized with the use of $25 \%$ trypsin solution (SIGMA) and afterwards they were stained with trypan blue (SIGMA) and counted in Buerker chamber. The density of the A-431 cell line and the HT-29 cell line used for the experiment was $1 \times 10^{6} \mathrm{cell} / \mathrm{ml}$. The vitality of both tissue lines was $80 \%$.

GBS strains were cultured in TSB (Tryptic Soy Broth, DIFCO Laboratories) for the period of 18 hours under aerobic condition at the temperature of $37^{\circ} \mathrm{C}$ (Incubator CLN ECO, POL-ECO Aparatura). On completion of incubation 18-hour GBS cultures were centrifuged (10 minutes, $3000 \mathrm{rpm}$ ) (SIGMA), washed three times with PBS without $\mathrm{Ca}^{2+}$ and $\mathrm{Mg}^{2+}$ (IITD PAN) and subsequently suspended in the medium mixture in ratio 1:1 of TSB : DMEM or TSB : RPMI 1640 depending on the requirement for tissue culture which participated in the experiment. The density of the obtained bacterial suspension was assessed with the use of spectrophotometric measurement (Spectrophotometer UV/VIS $\mathrm{V}-550$, Jasco) at wavelength of $600 \mathrm{~nm}$ within the range of $0.6-0.7$ and it was $1 \times 10^{8}$ c.f.u./ml (colony forming units per one mililitre).

The experiment was made by connecting the bacterial culture of the density of $1 \times 10^{8}$ c.f.u. $/ \mathrm{ml}$ with A-431 cell culture and the HT-29 cell culture of the cell densities of $1 \times 10^{6} / \mathrm{ml}$ in ratio 1:100. The strains of S. agalactiae DSMZ 2134, S. agalactiae ATCC 12403 and S. agalactiae ATCC BAA-611 constituted the positive control whereas the negative one was PBS without $\mathrm{Ca}^{2+}$ $\mathrm{i} \mathrm{Mg}^{2+}$. After 30 minutes of incubation at the temperature of $37^{\circ} \mathrm{C}$ in the atmosphere of increased humidity and $5 \%$ carbon dioxide concentration the culture with adherent GBS cells was washed three times with PBS, fixed in $3.7 \%$ formaldehyde $(\mathrm{POCH})$ and stained with the use of the Gram method (ANALAB). The adherence was quantitatively determined by counting GBS cells in 20 randomly selected fields of vision. The mean $(\overline{\mathrm{x}})$ for 20 fields constituted the final result (Strus et al., 2001).

To analyse the results the following techniques in the inductive statistics were applied: analysis of variance (ANOVA) and a supplementary post hoc analysis with the Tukey-Kramer test (Sokal and Rolf, 1995; Ferguson and Takane, 2009). If the distribution of numeric variable differed significantly from Gaussian curve the nonparametric alternatives to the above-mentioned tests were applied: the Kruskal-Wallis test as an alternative to ANOVA and Steel test instead of the Tukey-Kramer

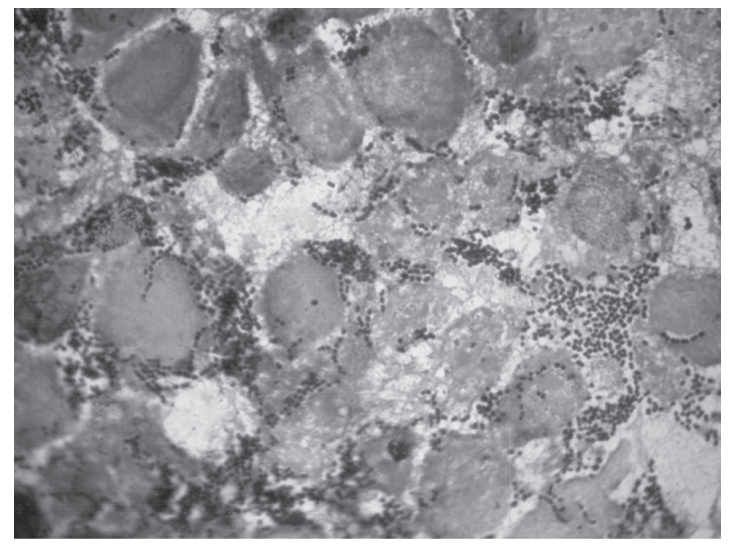

Fig. 1. Microscopic image of the A-431 cell line with adherent S. agalactiae ATCC BAA-611 strain (serotype V, rib gene).

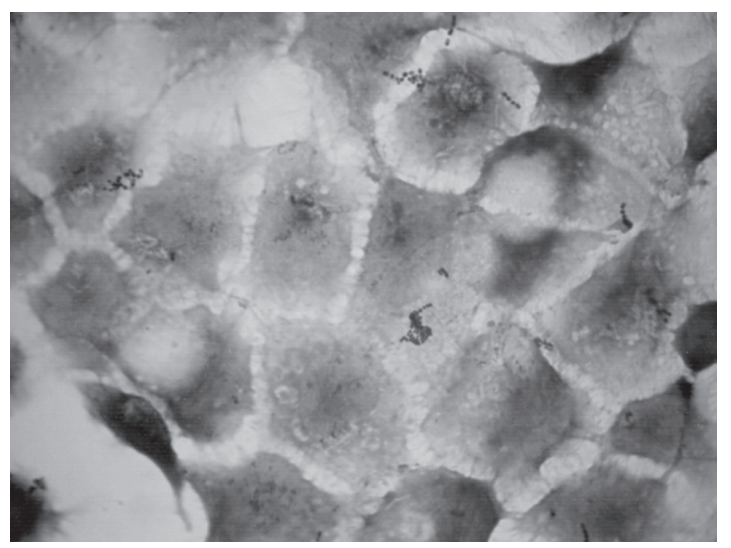

Fig. 2. Microscopic image of the A-431 cell line with adherent S. agalactiae ATCC BAA-611 strain (serotype V, rib gene).

test. The statistical procedures were conducted with JMP 7.01 (SAS Institute Inc.) (Stevens, 1989).

The adherence of selected 26 GBS strains and reference strains of S. agalactiae to the cell line of HT-29 human colon adenocarcinoma as well as the A-431 human epidermoid vulvo-vaginal cells was examined (Fig. 1, Fig. 2).

All the bacterial strains of S. agalactiae selected for the experiment adhered to both HT-29 and A-431 cell lines. There were statistically significant differences between S. agalactiae strains of the following serotypes: Ia, Ib, II, III and V $(P=0.0460)$ as well as between GBS strains with specific alpha-like protein genes (alp 2, alp 3, bca, epsilon, rib) $(P=0.0038)$ in adherence to both HT-29 and A-431 cell lines which would confirm the relation between the adherence of GBS and capsular polysaccharides (Fig. 3) as well as alpha-like protein genes (Fig. 4). Further analysis of the obtained results displayed statistically significant differences in the adherence to the HT-29 and A-431 


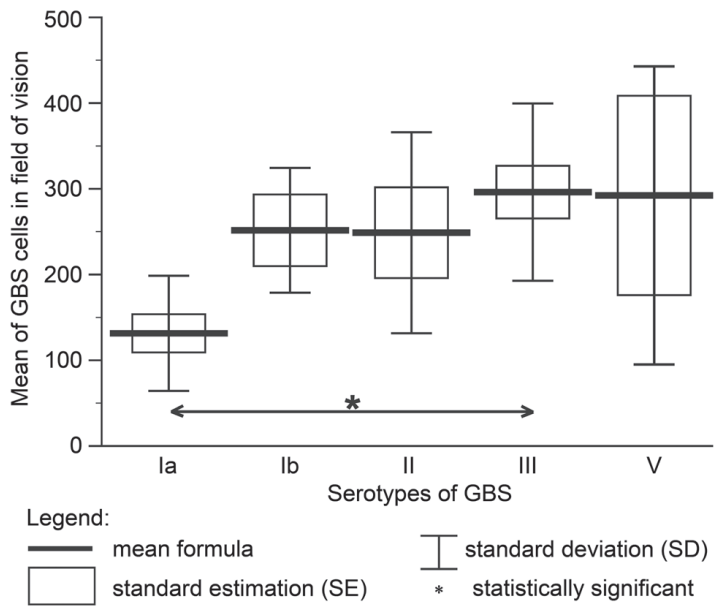

Fig. 3. The comparison of adherence of S. agalactiae strains belonging to the following serotypes: Ia, Ib, II, III and V to the HT-29 and A-431 cell lines.

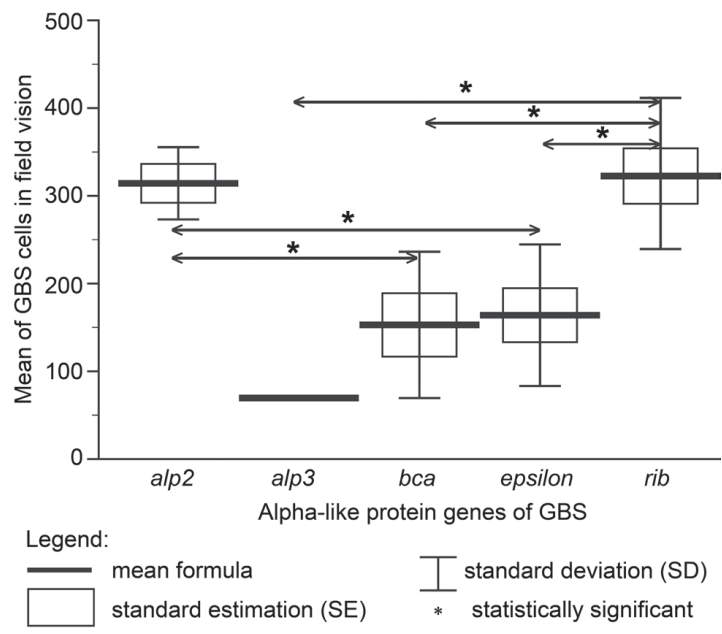

Fig. 4. The comparison of adherence of S. agalactiae strains in relation to the alpha-like protein genes to the HT-29 and A-431 cell lines. To assess the adherence described in this work the sole GBS strain possessing the alp 3 gene was selected.

cell lines between GBS strains of the serotypes of Ia and III $(P<0.05)$ (Fig. 5). Statistically significant differences were also confirmed between GBS strains possessing the rib gene and GBS strains with the following genes: alp 3, bca and epsilon as well as between GBS strains possessing the alp 2 gene and GBS strains with the epsilon and $b c a$ genes.

The presented analysis of results confirmed statistically significant higher adherence capacities of GBS to the HT-29 cell line corresponding to the properties of the colonic epithelium than to the A-431 cells representing the model of the vaginal epithelium $(P=0.0005)$. GBS strains of the following serotypes: Ia $(P=0.0462)$ and III $(P=0.0270)$ differed in adherence

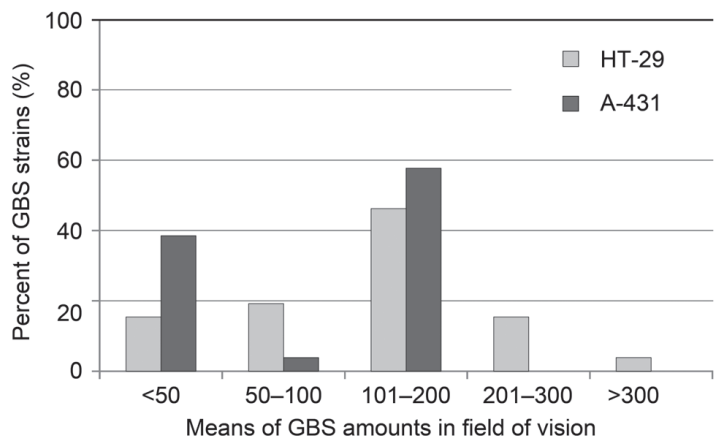

Fig. 5. The comparison of adherence of GBS between the HT-29 and A-431 cell lines.

capacities between the HT-29 and A-431 cell lines. GBS strains possessing the rib gene displayed differences in adherence capacities to the HT-29 and A-431 cell lines from GBS strains with the alp 2, alp 3, bca and epsilon genes $(P=0.0102)$.

Analysis of the adherence results of the selected GBS strains to the A-431 cell line confirmed the relation between adherence capacities of GBS strains and capsular polysaccharides $(P=0.0355)$ as well as alphalike protein genes $(P=0.0013)$. Statistically significant differences were demonstrated between GBS strains of serotype III which displayed the highest adherence capacities and GBS strains belonging to serotype Ia which displayed the lowest adherence to both cell lines $(P<0.05)$. GBS strains possessing the alp 2 and rib genes displayed higher adherence to the A-431 cell line unlike GBS strains with the alp3 gene.

On the other hand, adherence of the selected GBS strains to the HT-29 cell line depended solely on the alpha-like protein genes $(P=0.0373)$. GBS strains possessing the alp 2 and rib genes displayed higher adherence capacities to the HT-29 cell lines than GBS strains with the epsilon and $b c a$ genes $(P<0.05)$.

Analysis of the relationship between bacterial adhesion and capsular adhesins is very important to understanding of the infection process. All the GBS strains selected for the experiment adhered both to the HT-29 cell line corresponding to the properties of the colonic epithelium as well as to the A-431 cell line representing the model of the vaginal epithelium.

The observed adherence capacities of GBS are strains attributes so they indicate immense diversity among the analysed feature. The obtained results of GBS adherence for statistical analysis were averaged and then compared between investigated groups depending on serotype and presence of alpha-like protein genes. Presumably, adherence capacities of the examined GBS strains stemmed from the fact that they had been isolated from clinical materials of human origin. Similarly, Strus et al. (2001) examined the adherence of Lactobacillus strains 
isolated from the human flora to the A-431 and Caco-2 cell lines and they confirmed adherence capacities in most analyzed strains.

The observed higher adherence of GBS to the HT-29 cell line than to the A- 431 cell line can be accounted by the fact that GBS colonizes mainly the lower part of the gastrointestinal tract and vaginal colonization is a result of this process. In addition, this relation may result from differences in the structure of intestinal epithelial cells and vaginal epithelial cells as well as the presence of various receptors characteristic for a specific tissue (Kim etal., 2010). This can be confirmed by the fact that the relation between GBS adherence to the A-431 cell line and serotype as well as the alpha-like protein genes has been observed whereas for GBS adherence to the HT-29 cell line its sole dependence on the alpha-like protein genes has been noted.

The results of numerous examinations consisting in, among other things, preliminary effects of trypsin on GBS cells, application of antibodies against specific GBS adhesins or heat treatment of GBS at the temperature of $65^{\circ} \mathrm{C}$ for the period of 30 minutes resulted in a considerable decrease in bacterial adherence to the tissues in comparison to the strains which did not undergo the above-mentioned processes which would suggest an important role of proteins in the process of adhesion (Tamura et al., 1994). The results obtained in this work confirm the relation between the adherence of GBS strains to the A-431 and HT-29 cell lines and the presence of specific genes encoding the alpha-like proteins with particular attention to GBS strains possessing the rib gene. However, there are scientific reports describing a significant role of another alpha-like protein Alpha C protein - in the process of adherence. The Alpha $\mathrm{C}$ protein binds glycosaminoglycan on the surface of the host cells, which consequently allows the bacteria to penetrate into the epithelial cells. However other data indicated that GBS lacking bca gene was not affected in adhesion to epithelial cells (Baron et al., 2004; Bolduc et al., 2002). To assess the adherence described in this work the sole GBS strain possessing the alp 3 gene was selected due to the lack of GBS strains with this gene.

Perhaps alpha-like proteins play a helpful role in GBS adherence characteristic for a strain, because individual alpha-like proteins are not present in all GBS strains. Other GBS surface adhesins binding specific extracellular matrix (ECM) proteins are, among others, fibrinogen-binding proteins (FbsA and FbsB), laminin-binding proteins $(\mathrm{Lmb})$, serine-rich repeat proteins, peptidase (SepB) and fimbriae (Devi et al., 2010; Gutekunst et al., 2004; Tannenbaum et al., 2007; Samen et al., 2007).

Capsular polysaccharides conditioning the affinity of a specific GBS strain to serotype probably do not have a direct influence on its adherence properties. However, it is speculated that there can be specific adhesion proteins in a given serological type. Presumably, this could justify the relation between GBS adherence to the cell lines, capsular polysaccharides conditioning the affinity of the GBS strain to the specific serotype. For instance, among GBS strains of serotype III which is most frequently described as an etiological factor of neonatal infections, the restriction digested pattern type III strains of GBS which possess additional glycosylated proteins of adhesin-like functions were characterized (Seifert et al., 2006; Anderson et al., 2003).

The results of the presented experiment confirm the interesting relation between the adherence of $S$. agalactiae to the A-431 and HT-29 cell lines displaying the properties, respectively, of the vaginal epithelium as well as colonic epithelium and serotypes as well as the alpha-like protein genes. As a result, assessment of the adherence of GBS requires continuation consisting in examining more strains of S. agalactiae and including other tissue models in the research. Discovering the interaction which takes place between GBS cells and the epithelial cells of the host which condition the adherence as well as describing the adhesins and receptor proteins participating in this process would provide extremely valuable information. The obtained information could be used in the research on eradication of GBS from the genital tract as well as gastrointestinal tract of the pregnant women providing the protection for the baby against the infection.

\section{Acknowledgments}

This study was supported partially by grants from the Polish Ministry of Research and Higher Education no. N N401 042337 and no. N N401 042938.

\section{Literature}

Anderson E.E., S. Takahashi, Y. Wang, J. Amstrong, D.V. Miller and J.F. Bohnsack J. 2003. Subtractive hibridization identifies a novel predicted protein mediating epithelial cell invasion by virulent serotype III group B Streptococcus agalactiae. Infect. Immun. 71: 6857-6863

Baron M.J., G.R. Bolduc, M.B. Goldberg, T.C. Auperin and L.C. Madoff. 2004. Alpha C protein of group B binds host cell surface glycosaminoglycan and enters cells by an actin-dependent mechanism. J. Biol. Chem. 279: 24714-24723.

Bolduc G.R., M.J. Baron, C.J. Gravekamp, C.F. Lachenauer and L.C. Madoff. 2002. The alpha $\mathrm{C}$ protein mediates internalization of group B Streptococcus within human cervical epithelial cells. Cell Microbiol. 4: 751-758.

Creti R., F. Fabretti, G. Orefici and C. Hunolstein. 2004, Multiplex PCR assay for direct identification of group B streptococcal alphaprotein-like protein genes. J. Clin. Microbiol. 42: 1326-1329.

Devi A.S. and K. Ponnuraj. 2010. Cloning, expression, purification and ligand binding studies of novel fibrinogen-binding protein FbsB of Streptococcus agalactiae. Protein Expr. Purif. 74: 148-155.

Ferguson R. and Y. Takane. 2009. Statistical analysis in psychology and education (in Polish). Polish Scientific Publishers PWN. 
Gherardi G., M. Imperi, L. Baldassarri, M. Pataracchia, G. Alfarone, S. Recchia, G. Orefici, G. Dicuonzo and R. Creti . 2007. Molecular epidemiology and distribution of serotypes, surface proteins, and antibiotic resistance among Group B streptococci in Italy. J. Clin. Microbiol. 45: 2909-2916.

Gutekunst H., B.J. Eikmanns and D.J. Reinscheid. 2004. The novel fibrinogen-binding protein $\mathrm{FbsB}$ promotes Streptococcus agalactiae invasion into epithelial cells. Infect. Immun. 72: 3495-3504.

Harrison L.H., J.A. Elliott, D.M. Dwyer, J.P. Libonati, P. Ferrieri, L. Billmann and A. Schuchat. 1998. Serotype distribution of invasive group B streptococcal isolates in Maryland: implications for vaccine formulation. J. Infect. Dis. 177: 998-1002

Hickman M.E., M.A. Rench, P. Ferrieri and C.J. Backer. 1999. Changing epidemiology of group B streptococcal colonization. Pediatrics. 104: 203-209.

Kim M., H. Ashida, M. Ogawa, Y. Yoshikawa, H. Mimuro and C. Sasakawa. 2010. Bacterial interactions with the host epithelium. Cell. Host. Microbe 8: 20-35.

Lachenauer C.S., R. Creti, J.L. Michel and L.C. Madoff. 2000. Mosaicism in the alpha-like protein genes of group B streptococci. Proc. Natl. Acad. Sci. 97: 9630-9635.

Lione V.O., G.S. Santos, R. Hirata Junior, A.L. Mattos-Guaraldi and P.E. Nagao. 2005. Involvement of intracellular adhesion molecule- 1 and betal integrin in the internalization process to human endothelial cells of group B Streptococcus clinical isolates. Int. J. Mol. Med. 15: 153-157.

Persson E., S. Berg, L. Bevanger, K. Bergh, R. Valsö-Lyng and B. Trollfors. 2008. Characterisation of invasive group B streptococci based on investigation of surface proteins and genes encoding surface proteins. Clin. Microbiol. Infect. 14: 66-73.

Poyart C., A. Tazi, H. Reglier-Poupet, A. Billoët, N. Tavares, J. Raymond and P. Trieu-Cuot. 2007. Multiplex PCR assay for rapid and accurate capsular typhing of group B streptococci. J. Clin. Microbiol. 45: 1985-1988.

Samen U., B.J. Eikmanns, D.J. Reinscheid and M. Borges. 2007. The surface protein Srr-1 of Streptococcus agalactiae binds human keratin 4 and promotes adherence to epithelial HEp- 2 cells. Infect Immun. 75: 5405-5414.

Schrag S.J., S. Zywicki, M.M. Farley, A.L. Reingold, L.H. Harrison, L.B. Lefkowitz, J.L. Hadler, R. Danila, P.R. Cieslak and
A. Schuchat. 2000. Group B streptococcal disease in the era of intrapartum antibiotic profilaxis. N. Engl. J. Med. 342: 15-20.

Seifert K.N., E.F. Adderson, A.A. Whiting, J.F. Bohnsack, P.J. Crowley and L.J. Brady. 2006. A unique serine-rich repeat protein (Srr-2) and novel surface antigen $(\varepsilon)$ associated with a virulent lineage of serotype III Streptococcus agalactiae. Microbiol. 152: 1029-1040.

Slotved H.C., F. Kong, L. Lambertsen, S. Sauer and G.L. Gilbert. 2007. Serotype IX, a proposed new Streptococcus agalactiae serotype. J. Clin. Microbiol. 45: 2929-2936.

Sohn K., I. Senyuerek, J. Fertey, A. Königsdorfer, C. Joffroy, N. Hauser, G. Zelt, H. Brunner and S. Rupp. 2006. An in vitro assay to study the transcriptional response during adherence of Candida albicans to different human epithelia. FEMS Yeast Res. 6: 1085-1093.

Sokal R.R. and F.J. Rohlf. 1995. Biometry: the principles and practice of statistics in biological research. $3^{\text {rd }}$ edition; W. H. Freeman and Co.: New York. 887 pp. ISBN: 0-7167-2411-1.

Stevens G. 1989. A nonparametric multiple comparison test for differences in scale parameters. Metrika. 36: 91-106.

Strus M., G. Kukla, D. Rurańska-Smutnicka, A. Przondo-Mordarska and P.B. Heczko. 2001. The surface properties of Lactobacillus. II Adherence to tissue culture surfaces and their electron microscopic appearance (in Polish). Exp. Med. Microbiol. 3: 253-258. Tamura G.S., J.M. Kuypers, S. Smith, H. Raff and C.E. Rubens. 1994. Adherence of group B streptococci to cultured epithelial cells: roles of environmental factors and bacterial surface components. Infect. Immun. 62: 2450-2458.

Tenenbaum T., B. Spellerberg, R. Adam, M. Vogel, K.S. Kim and A. Schroten. 2007. Streptococcus agalactiae invasion of human brain microvascular endothelial cell is promoted by the laminin-binding protein Lmb. Microbes Infect. 9: 714-720.

Verani J.R., L. McGee and S.J. Schrag. 2010. Division of Bacterial Diseases, National Center for Immunization and Respiratory Diseases, Centers Control for Disease and Prevention. MMWR Recom. Rep. 59: 1-36.

Zaleznik D.F., M.A. Rench, S. Hillier, M.A. Krohn, R. Platt, M.L. Lee, A.E. Flores, P. Ferrieri and C.J. Baker. 2000. Invasive disease due to Group B streptococcus in pregnant women and neonates from diverse population groups. Clin. Infect. Dis. 30: 276-281. 